\title{
At the frontier of climate change: Red alert from the European Alps, the Arctic and coral reefs
}

\author{
This article belongs to Ambio's 50th Anniversary Collection. Theme: Climate change \\ impacts
}

\author{
Angela Wulff
}

Published online: 1 March 2021

Evidence of climate change first became apparent in the more sensitive ecosystems around the world. These systems have since then been used in research to highlight how the climate has developed historically, what the current situation is, and what is likely to happen in the near and distant future.

For decades, signals of warming have been recorded in high alpine areas. Glaciers are melting at an accelerating pace (Haeberli and Beniston 1998) and current research predicts that most glaciers in the European Alps will be gone by the year 2100 (Zekollari et al. 2019). The effects of climate change are also evident in coral reefs around the world, where rising sea surface temperatures cause increasingly frequent and damaging bleaching events (Goreau and Hayes 1994). At the regional scale, the pace of warming is faster in the polar regions than the global average. This has now led to profound shifts in the distribution of plant and animal species-terrestrial as well as aquatic (IPCC 2013).

Although climate change is evident, determining the effects it has is in itself difficult as it is entangled with other large-scale environmental changes. For example, high $\mathrm{CO}_{2}$ concentrations lead also to ocean acidification. This creates what is often referred to as "the other $\mathrm{CO}_{2}$ problem" (Caldeira and Wickett 2003) - a lower buffering capacity. Together, increasing temperature and acidification result in accelerating cascade effects in marine ecosystems and may cause sudden shifts in the structure and function of ecosystems. Such dramatic shifts are visible in most coral reefs as they are pushed closer to the final tipping point where the reefs are beyond recovery (Hoegh-Guldberg et al. 2007; Smith et al. 2020; Goreau and Hayes 2021). Scientists studying such systems were among the first to raise alarm and warn about the consequences of global warming for diverse ecosystems and the people inhabiting or depending on them for their livelihoods.

The number of publications concerning "climate change" in the database Web of Science "Environmental Sciences" and "Meteorology Atmospheric Sciences", has increased from less than 10 publications per year between 1945 and 1985, to well over 1000 from 2003, peaking with over 10000 per year after $2017 .{ }^{1}$ Climate change has also received more attention in Ambio, with on average 32 publications per year during the previous decade.

In this anniversary collection, we present four highly cited Ambio papers that were important for the early discovery and understanding of climate change effects in three types of ecosystems; coral reefs (Goreau and Hayes 1994), European Alps (Haeberli and Beniston 1998), and the terrestrial Arctic (Callaghan et al. 2004, 2011). The authors of these four papers offer their personal views and behind the paper stories (Callaghan and Johansson 2021; Goreau and Hayes 2021; Haeberli and Beniston 2021). In addition, three other scientists reflect on the four papers and put them in perspective (Chen 2021; Bjorkman and Wulff 2021). Taken together, these papers provide evidence of the escalating effects of climate change on vulnerable ecosystems worldwide-and the signals we receive are deep red.

The Ambio papers highlighted in this anniversary collection also argue for improving the monitoring of abiotic as well as biotic facets of climate change impacts (see below). A number of such initiatives to monitor climate change are now in place: the Circumpolar Biodiversity Monitoring Program $\left(\mathrm{CBMP}^{2}\right)$, developed by the

\footnotetext{
${ }^{1}$ Key word "climate change" in the database Web of Science, November 5, 2020.

${ }^{2}$ https://www.caff.is/monitoring.
} 
Conservation of Arctic Flora and Fauna working group of the Arctic Council (marine, freshwater, terrestrial, and coastal ecosystems in the Arctic), the Global Mountain Biodiversity Assessment $\left(\mathrm{GMBA}^{3}\right)$, and the Global Coral Reef Monitoring Network $\left(\mathrm{GCRMN}^{4}\right)$. The results from these and other research efforts are used by the Intergovernmental Panel on Climate Change (IPCC) to regularly publish state-of-the-art climate change updates, such as the recent special report on the ocean and cryosphere in a changing climate (IPCC 2019). This report presented the most recent assessments of climate-related risks for oceans, polar and high mountain regions. For coral reefs, a further loss of $70-90 \%$ at $1.5{ }^{\circ} \mathrm{C}$ global warming is anticipated, Arctic sea ice will continue to melt, and small glaciers (e.g. in the European Alps) are projected to disappear by 2100 (IPCC 2019). The occurrence of multifactorial effects makes scientists less certain about how ecosystems will respond to these changes. For example, ocean acidification and reduced oxygen levels pose additive threats to coral reefs. Moreover, some locations in e.g. Arctic ecosystems, for reasons not yet clear, seem resistant to climate change (so far) (Taylor et al. 2020); something that needs to be further explored to gain knowledge on how to mitigate ongoing (negative) changes.

Climate change represents one of the most pressing societal and scientific challenges of our time. The four influential papers (Goreau and Hayes 1994; Haeberli and Beniston 1998; Callaghan et al. 2004, 2011) established baseline facts and helped raise awareness. There is now a broad consensus that trends of climate warming over the past century are caused by human activities, like the burning of fossil fuels (Oreskes 2004; Cook et al. 2016), and the majority of the world's leading scientific organisations have issued public statements endorsing this position. Young people around the world are making a strong call for action and so are the people living in the regions most affected by climate change effects. In the Paris Agreement 2015, the World leaders agreed to limit global warming, but these ambitions have not been fulfilled.

On the positive side, history demonstrates that we can act together and make changes for the common good. One such example is the Montreal Protocol on substances that deplete the ozone layer, adopted 1987, and today, the parties have phased out ca. $98 \%$ of ozone-depleting substances. Another example is the progress in reduction of emissions of acidifying sulfur and nitrogen oxides, which together with liming has led to gradual recovery of the chemistry and biology of inland waters (see Tranvik 2021).

If we want to, we can make changes.

\footnotetext{
${ }^{3}$ https://www.gmba.unibe.ch.

${ }^{4}$ https://gcrmn.net/.
}

\section{REFERENCES}

Bjorkman A., and A. Wulff. 2021. A reflection on four impactful Ambio papers: The biotic perspective. 50th Anniversary Collection: Climate Change Impacts. Ambio Volume 50. https://doi. org/10.1007/s13280-020-01442-5.

Caldeira, K., and M. Wickett. 2003. Anthropogenic carbon and ocean pH. Nature 425: 365. https://doi.org/10.1038/425365a.

Callaghan, T.V., and M. Johansson. 2021 The rise of the Arctic: Intergenerational personal perspectives. 50th Anniversary Collection: Climate Change Impacts. Ambio. Volume 50. https://doi. org/10.1007/s13280-021-01511-3.

Callaghan, T.V., L.O. Björn, Y. Chernov, F.S.T.R. Christensen, B. Huntley, R.A. Ims, M. Johansson, et al. 2004. Biodiversity, distributions and adaptations of Arctic species in the context of environmental change. Ambio 33: 404-417. https://doi.org/10. 1579/0044-7447-33.7.404.

Callaghan, T.V., M. Johansson, R.D. Brown, P.Y. Groisman, N. Labba, V. Radionov, R.G. Barry, O.N. Bulygina, et al. 2011. The changing face of Arctic snow cover: A synthesis of observed and projected changes. Ambio 40: 17-31. https://doi.org/10.1007/ s13280-011-0212-y.

Chen, D. 2021. Impact of climate change on sensitive marine and extreme terrestrial ecosystems: Recent progresses and future challenges. 50th Anniversary Collection: Climate Change Impacts. Ambio. Volume 50. https://doi.org/10.1007/s13280020-01446-1.

Cook, J., N. Oreskes, P.T. Doran, R. William, L. Anderegg, B. Verheggen, E.W. Maibach, J.S. Carlton, et al. 2016. Consensus on consensus: a synthesis of consensus estimates on humancaused global warming. Environmental Research Letters 11: 048002 .

Goreau, T.J., and R.L. Hayes. 1994. Coral bleaching and ocean "hot spots". Ambio 23: 176-180.

Goreau, T.J., and R.L. Hayes. 2021 Global warming triggers coral reef bleaching tipping point. 50th Anniversary Collection: Climate Change Impacts. Ambio. Volume 50. https://doi.org/ 10.1007/s13280-021-01512-2.

Haeberli, W., and M. Beniston. 1998. Climate change and its impacts on glaciers and permafrost in the Alps. Ambio 27: 258-265.

Haeberli, W., and M Beniston. 2021. Icy mountains in a warming world: Revisiting science from the end of the 1990s in the early 2020s. 50th Anniversary Collection: Climate Change Impacts. Ambio. Volume 50. https://doi.org/10.1007/s13280-021-01513-1.

Hoegh-Guldberg, O., P.J. Mumby, A.J. Hooten, R.S. Steneck, P. Greenfield, E. Gomez, C.D. Harvell, P.F. Sale, et al. 2007. Coral reefs under rapid climate change and ocean acidification. Science. https://doi.org/10.1126/science.1152509.

IPCC. 2013. Climate Change 2013: The Physical Science Basis. Contribution of Working Group I to the Fifth Assessment Report of the Intergovernmental Panel on Climate Change, eds. T.F. Stocker, D. Quin, G.-K. Plattner, M. Tignor, S.K. Allen, J. Boschung, A. Nauels, Y. Xia, et al. Cambridge: Cambridge University Press.

IPCC. 2019. Summary for policymakers. In IPCC Special Report on the Ocean and Cryosphere in a Changing Climate, eds. H.-O. Pörtner, D.C. Roberts, V. Masson-Delmotte, P. Zhai, M. Tignor, E. Poloczanska, K. Mintenbeck, A. Alegría, et al., pp 3-35. In press.

Oreskes, N. 2004. The scientific consensus on climate change. Science. https://doi.org/10.1126/science.1103618.

Smith, J.N., M. Mongin, A. Thompson, M.J. Jonker, G. De'Ath, and K.E. Fabricius. 2020. Shifts in coralline algae, macroalgae, and coral juveniles in the Great Barrier Reef associated with present- 
day ocean acidification. Global Change Biology. https://doi.org/ 10.1111/gcb.14985.

Taylor, J.J., J.P. Lawler, M. Aronsson, T. Barry, A.D. Bjorkman, T. Christensen, S.J. Coulson, C. Cuyler, et al. 2020. Arctic terrestrial biodiversity status and trends: A synopsis of science supporting the CBMP State of Arctic Terrestrial Biodiversity Report. Ambio 49: 833-847. https://doi.org/10.1007/s13280-01901303-w.

Tranvik, L.J. 2021 Acidification of inland waters. 50th Anniversary Collection: Acidification. Ambio volume 50. https://doi.org/10. 1007/s13280-020-01441-6.

Zekollari, H., M. Huss, and D. Farinotti. 2019. Modelling the future evolution of glaciers in the European Alps under the EUROCORDEX RCM ensemble. The Cryosphere 13: 1125-1146.

Publisher's Note Springer Nature remains neutral with regard to jurisdictional claims in published maps and institutional affiliations.

\section{AUTHOR BIOGRAPHY}

Angela Wulff $(\bowtie)$ is a Professor at the Department of Biological and Environmental Sciences at the University of Gothenburg. Her research interests include ecophysiological effects of climate change, including ocean acidification and effects of UV radiation, on marine microalgae and cyanobacteria, in polar as well as temperate regions. Address: Department of Biological \& Environmental Sciences, Box 461, 40530 Gothenburg, Sweden.

e-mail: angela.wulff@bioenv.gu.se 
Article Thomas J. Goreau and Raymond L. Hayes

\title{
Coral Bleaching and Ocean "Hot Spots"
}

Global sea-surface temperature maps show that mass coral-reef bleaching episodes between 1983 and 1991 followed positive anomalies more than $1^{\circ} \mathrm{C}$ above long-term monthly averages ("hot spots") during the preceding warm season. Irregular formation, movement, and disappearance of hot spots make their detailed long-term prediction impossible, but they can be tracked in real time from satellite data. Monitoring of ocean hot spots and of coral bleaching is needed if the Framework Convention of Climate Change is to meet its goal of protecting the most temperaturesensitive ecosystems.

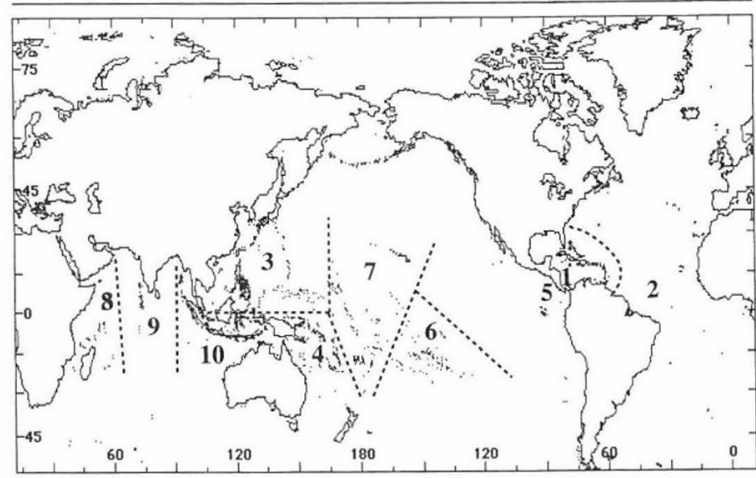

Figure 1a. Reef regions of the world, divided into 10 major reef provinces of roughly comparable area. These regions do not necessarily correspond to biogeographic provinces.

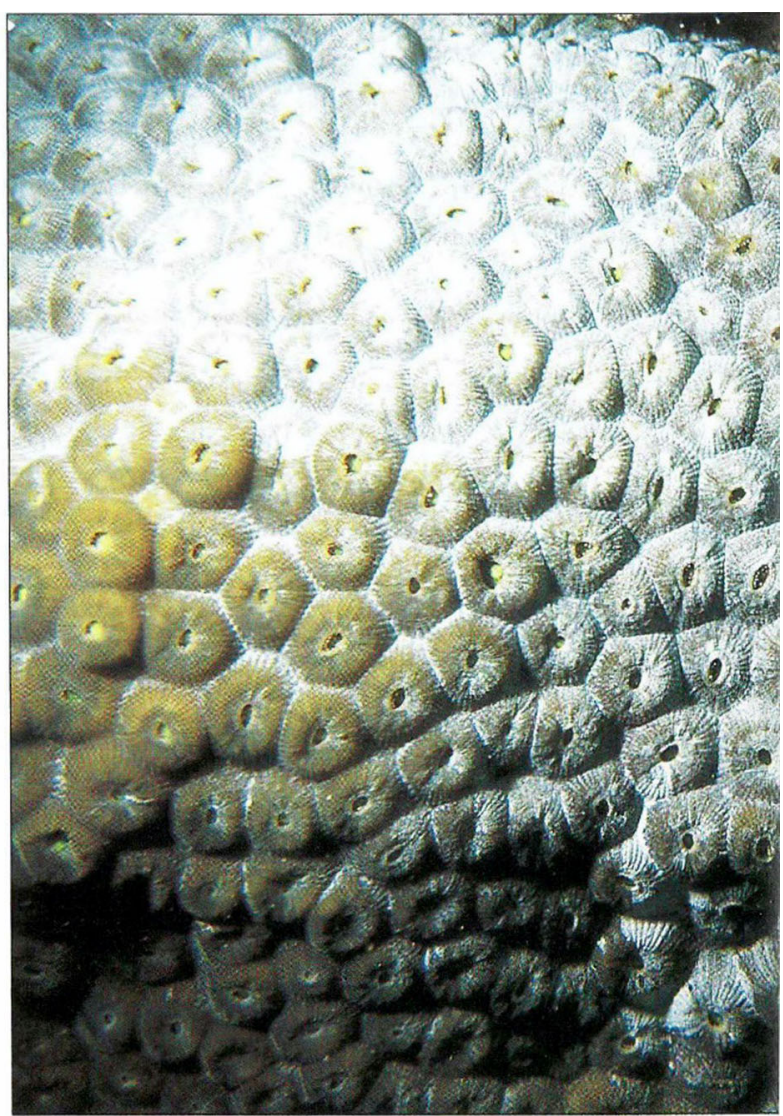

\section{CORAL BLEACHING EVENTS}

Coral-reef bleaching (1-13), or expulsion of symbiotic zooxanthellae algae, became more frequent, widespread, and severe in the 1980s $(6-13)$. Zooxanthellae provide reef corals most of their carbon $(14,15)$, limestone depositing ability (16), and color (17). Bleaching causes corals to turn white or pale, because loss of pigment allows the limestone skeleton to become visible through transparent tissues. Local bleaching due to poor water circulation (1-3) or freshwater and sediment from rivers (4,

$$
\begin{aligned}
& \text { REGION VEAR: } 79808182838485868788899091
\end{aligned}
$$

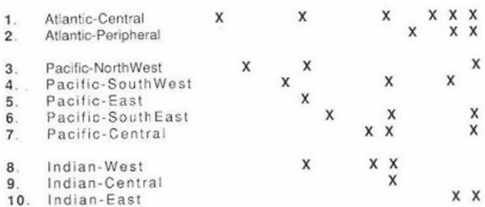

Figure 1b. Major bleaching events reported in reef regions since 1979. Bleaching events are taken from published citations and summaries in reference 6 , updated by more recent reports from divers and scientists around the world compiled by Ernest Williams (pers. comm.). Local bleaching events are included until 1982, but not afterwards, making any increase in events conservative estimates.

\author{
Figure 1c. Frequency \\ of worldwide \\ bleaching events \\ since 1979 . In the early \\ 1980 s, most reported \\ bleaching events took \\ place in only one reef \\ province per year. In \\ the late 1980 s, \\ bleaching events \\ occurred at sites in \\ around half of all reef \\ provinces every year.
}

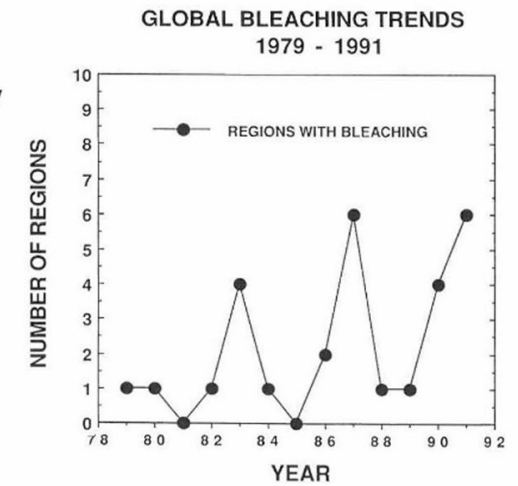




\section{Climate Change and Its Impacts on Glaciers and Permafrost in the Alps}

Climate change in the European Alps during the 20th century has been characterized by increases in minimum temperatures of about $2^{\circ} \mathrm{C}$, a more modest increase in maximum temperatures, little trend in precipitation data, and a general decrease of sunshine duration through to the mid-1980s. Temperature increase has been most intense in the 1940s, followed by the 1980s. The warming experienced since the early 1980 s, while synchronous with the global warming, is of far greater amplitude and reaches close to $1^{\circ} \mathrm{C}$ for this ensemble average and up to $2^{\circ} \mathrm{C}$ for individual sites. Such changes caused pronounced effects in the glacial and periglacial belts. Since the middle of the past century-the end of the Little Ice Age-the glacierization of the European Alps has lost about 30 to $40 \%$ in surface area and around half its original volume. The estimated total glacier volume in the European Alps was some $130 \mathrm{~km}^{3}$ for the mid-1970s, but strongly negative mass balances have caused an additional loss of about 10 to $20 \%$ of this remaining ice volume since 1980 . Periglacial permafrost in the Alps today occupies an area comparable to the glacierized area and must have been affected as well, but its secular evolution is much less well known. Simulations of high-resolution climatologies for double- $\mathrm{CO}_{2}$ situations using regional climate models (RCM) with a $20-\mathrm{km}$ horizontal grid give generally higher winter temperatures, a more marked increase in summer temperatures, indications that temperature increases more at higher elevations than at lower altitudes, and higher/ more intense precipitation in winter, but much dryer conditions in summer. Under such conditions, the Alps would lose major parts of their glacier cover within decades, warming of cold firn areas at high altitudes could become pronounced and lower limits of permafrost occurrence in the Alps could rise by several hundred meters. Pronounced disequilibria could result, in the water cycle, in mass wasting processes, and in sediment flux as well as in growth conditions of vegetation. For those directly involved with such changes, the main challenge would be to adapt to high and accelerating rates of environment evolution. Empirical knowledge would have to be replaced increasingly by improved process understanding, especially concerning runoff formation and slope stability. In view of the uncertainties involved with future projections, highest priority should be given to appropriate monitoring programs.

\section{INTRODUCTION}

Mountain systems cover about one-fifth of the earth's continental areas. Mountains provide direct life support for close to $10 \%$ of the world's population and, indirectly, to over $50 \%$. Mountains are also a key element of the hydrological cycle, being the source of many of the world's major river systems. Snow, glaciers and permafrost in cold mountain areas are especially sensitive with respect to changes in atmospheric conditions, because of their proximity to melting conditions. In addition, mass wasting is most intensive in high mountain areas with steep slopes. As a consequence, climatic changes cause pronounced effects in the glacial and periglacial belts of mountain areas. The 20th century has seen striking changes in glacierized areas of mountain ranges and, hence, in the extension of glacial and periglacial mountain belts all over the world. The changes in surface and ground ice conditions caused a corresponding shift in geomorphic processes. This development was accompanied by the increasing activities of man in cold high mountain ranges. It is, in fact, the combination of ice vanishing and human impact, which has introduced the most striking changes in high mountain landscapes during recent times.

The European Alps are among the most densely populated and most intensively studied mountain ranges of the world. As a consequence, effects of climate change on high-mountain environments and living conditions are especially well documented. The interest focuses on signals which become visible in an area of highest climatic sensitivity, and which reflect complex changes at a global scale. In addition, concern increases in view of potential impacts from continuing or potentially accelerating climatic changes. The present report summarizes the most important aspects relating to climate change, glaciers and permafrost in the Alps. It is based on earlier assessments by Beniston et al. (1), Fitzharris et al. (2) and Haeberli $(3,4)$.

\section{BACKGROUND}

Although mountains may appear to be mere roughness elements on the earth's surface, they are in fact an important element of the climate system. They are one of the trigger mechanisms of cyclogenesis in mid-latitudes, through their perturbations of large-scale atmospheric flow patterns. A precise understanding of the climatic characteristics of mountain regions is complicated on the one hand by a lack of observational data at the spatial and temporal resolution adequate for climate research in regions of complex topography, and on the other by the considerable difficulty in representing complex terrain in current general circulation climate modeIs (GCMs). Mountains also have an influence on the formation of clouds and precipitation in their vicinity, which are in turn indirect mechanisms of heat and moisture transfer in the vertical. Consequently, the influence of orography on climate needs to be taken into account in a physically meaningful manner. Parametric schemes in GCMs take a number of possible forms, such as "envelope topography" which smooths the real orography over continental areas. Large-scale orographic forcing is then derived by filtering the orography at smaller scales and dynamic influences of boundary-layer turbulence. Gravity waves generated by the presence of the underlying orography on the atmosphere are capable of breaking in a similar manner to ocean waves at the seashore, and in doing so transfer substantial quantities of momentum from the large-scale to the small-scale flows. Meteorological research has tended to focus on the upstream and downstream influences of barriers to flow, and on orographic effects on weather systems (5), rather than on the specificities of climate within the mountain environments themselves. These include microclimatological processes which feed into the large-scale flows, and the feedbacks between the surface and the atmosphere, particularly vegetation and geomorphologic features, which can create microclimatic contrasts in surface heating, soil moisture or snow-cover duration (6). However, isolating macro-and microscale processes, in order to determine their relative importance, is complicated by inadequate data bases for most mountain areas of the world (7).

In the chain of processes linking climate and glacier fluctuations, glacier mass change is the direct/undelayed reaction, 
Climate Change and UV-B Impacts on Arctic Tundra and Polar Desert Ecosystems

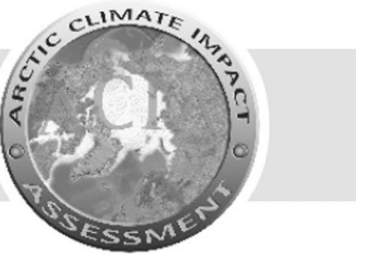

\section{Biodiversity, Distributions and Adaptations of Arctic Species in the Context of Environmental Change}

Terry V. Callaghan, Lars Olof Björn, Yuri Chernov, Terry Chapin, Torben R. Christensen, Brian Huntley, Rolf A. Ims, Margareta Johansson, Dyanna Jolly, Sven Jonasson, Nadya Matveyeva, Nicolai Panikov, Walter Oechel, Gus Shaver, Josef Elster, Heikki Henttonen, Kari Laine, Kari Taulavuori, Erja Taulavuori and Christoph Zöckler

\begin{abstract}
The individual of a species is the basic unit which responds to climate and UV-B changes, and it responds over a wide range of time scales. The diversity of animal, plant and microbial species appears to be low in the Arctic, and decreases from the boreal forests to the polar deserts of the extreme North but primitive species are particularly abundant. This latitudinal decline is associated with an increase in super-dominant species that occupy a wide range of habitats. Climate warming is expected to reduce the abundance and restrict the ranges of such species and to affect species at their northern range boundaries more than in the South: some Arctic animal and plant specialists could face extinction. Species most likely to expand into tundra are boreal species that currently exist as outlier populations in the Arctic. Many plant species have characteristics that allow them to survive short snow-free growing seasons, low solar angles, permafrost and low soil temperatures, low nutrient availability and physical disturbance. Many of these characteristics are likely to limit species' responses to climate warming, but mainly because of poor competitive ability compared with potential immigrant species. Terrestrial Arctic animals possess many adaptations that enable them to persist under a wide range of temperatures in the Arctic. Many escape unfavorable weather and resource shortage by winter dormancy or by migration. The biotic environment of Arctic animal species is relatively simple with few enemies, competitors, diseases, parasites and available food resources. Terrestrial Arctic animals are likely to be most vulnerable to warmer and drier summers, climatic changes that interfere with migration routes and staging areas, altered snow conditions and freeze-thaw cycles in winter, climate-induced disruption of the seasonal timing of reproduction and development, and influx of new competitors, predators, parasites and diseases. Arctic microorganisms are also well adapted to the Arctic's climate: some can metabolize at temperatures down to $-39^{\circ} \mathrm{C}$. Cyanobacteria and algae have a wide range of adaptive strategies that allow them to avoid, or at least minimize UV injury. Microorganisms can tolerate most environmental conditions and they have short generation times which can facilitate rapid adaptation to new environments. In contrast, Arctic plant and animal species are very likely to change their distributions rather than evolve significantly in response to warming.
\end{abstract}

\section{INTRODUCTION}

The impacts of changing climate and UV-B in the Arctic (1) will be observed at many levels of organization of the biological system, from individual metabolic processes to changes in vegetation zones and exchanges of energy, water and trace gases between the biosphere and the atmosphere $(2,3)$. However, it is the individual of a species that is the basic unit of ecosystems which responds to climate and UV-B changes. Individuals respond to environmental changes over a wide range of time scales from biochemical, physiological and behavioral processes occurring in less than a minute to the integrative responses of reproduction and death (Fig. 1 in ref. 2). Reproduction and death drive the dynamics of populations while mutation and environmental selection of particular traits in individuals within the population lead to changes in the genetic composition of the population and adaptation.

Current Arctic species have characteristics that have enabled them to pass various environmental filters associated with the Arctic's environment $(4,5)$, whereas species of more southern latitudes either cannot pass these filters or have not yet arrived in the Arctic. Changes in Arctic landscape processes and ecosystems in a future climatic and UV-B regime will depend upon the ability of Arctic species to withstand or adapt to new environments and upon their interactions with immigrant species that can pass through less severe environmental filters. This paper is part of an holistic approach to assess impacts of climate change on Arctic terrestrial ecosystems $(1,2)$. Here, we focus on the attributes of current Arctic species that are likely to constrain or facilitate their responses to a changing climate and UV-B regime.

\section{IMPLICATIONS OF CURRENT SPECIES DISTRIBUTIONS} FOR FUTURE BIOTIC CHANGE

Plants

\section{Species diversity}

About 3\% (about 5900) species of the global flora occurs in the Arctic as defined in this paper and others in this Ambio Special Issue $(0.7 \%$ of the angiosperms (flowering plants), $1.6 \%$ of the gymnosperms (cone-bearing plants), $4 \%$ of the bryophytes and $11 \%$ of the lichens) (Table 1). There are more species of primitive taxa (cryptogams) i.e. mosses, liverworts, lichens and algae in the Arctic than of vascular plants (6). Less than half of the Arctic plant species are vascular plants (about 1800 species). There are about 1500 species common to both Eurasia $(6,7)$ and North America (8). A similar number of nonvascular plants probably occurs in the Arctic on both continents, although their diversity has been less thoroughly documented. In the Russian Arctic, for example, 735 bryophyte species $(530$ mosses and 205 liverworts) and 1078 lichen species have been recorded (9-11). In general, the North American and Eurasian Arctic are similar to one another in their numbers of vascular and nonvascular 


\title{
The Changing Face of Arctic Snow Cover: A Synthesis of Observed and Projected Changes
}

\author{
Terry V. Callaghan, Margareta Johansson, Ross D. Brown, Pavel Ya. Groisman, \\ Niklas Labba, Vladimir Radionov, Roger G. Barry, Olga N. Bulygina, \\ Richard L. H. Essery, D. M. Frolov, Vladimir N. Golubev, Thomas C. Grenfell, \\ Marina N. Petrushina, Vyacheslav N. Razuvaev, David A. Robinson, \\ Peter Romanov, Drew Shindell, Andrey B. Shmakin, Sergey A. Sokratov, \\ Stephen Warren, Daquing Yang
}

\begin{abstract}
Analysis of in situ and satellite data shows evidence of different regional snow cover responses to the widespread warming and increasing winter precipitation that has characterized the Arctic climate for the past 40-50 years. The largest and most rapid decreases in snow water equivalent (SWE) and snow cover duration (SCD) are observed over maritime regions of the Arctic with the highest precipitation amounts. There is also evidence of marked differences in the response of snow cover between the North American and Eurasian sectors of the Arctic, with the North American sector exhibiting decreases in snow cover and snow depth over the entire period of available in situ observations from around 1950, while widespread decreases in snow cover are not apparent over Eurasia until after around 1980. However, snow depths are increasing in many regions of Eurasia. Warming and more frequent winter thaws are contributing to changes in snow pack structure with important implications for land use and provision of ecosystem services. Projected changes in snow cover from Global Climate Models for the 2050 period indicate increases in maximum SWE of up to $15 \%$ over much of the Arctic, with the largest increases (15-30\%) over the Siberian sector. In contrast, SCD is projected to decrease by about $10-20 \%$ over much of the Arctic, with the smallest decreases over Siberia $(<10 \%)$ and the largest decreases over Alaska and northern Scandinavia (30-40\%) by 2050 . These projected changes will have far-reaching consequences for the climate system, human activities, hydrology, and ecology.
\end{abstract}

Electronic supplementary material The online version of this article (doi:10.1007/s13280-011-0212-y) contains supplementary material, which is available to authorized users.
Keywords Snow depth - Snow water equivalent . Snow cover duration . Snow cover extent

\section{INTRODUCTION}

Frozen precipitation accumulating on a surface creates a snow cover. Snow is an important and dominant feature of Arctic terrestrial landscapes with cover present for $8-10$ months of the year. Its extent, dynamics, and properties (e.g., depth, density, water equivalent, grain size, and changes in structure throughout its vertical profile) affect climate (e.g., ground thermal regime), human activities (e.g., transportation, resource extraction, water supply, use of land, and ecosystem services), as well as infrastructure, hydrological processes, permafrost, extreme events (including hazards such as avalanches and floods), biodiversity, and ecosystem processes. Snow is therefore a significant component in the socio-economics of Arctic societies. The important physical properties that exert an influence on climate or moderate its effects (Cohen and Rind 1991) include high short-wave albedo, high thermal emissivity, low heat conductivity, large latent heat of fusion, and low surface roughness while it stores and rapidly releases water in the melt season. The combination of high albedo and low thermal conductivity promotes low surface temperatures and low-level temperature inversions. The low thermal conductivity of snow allows it to insulate the surface from large energy losses in winter, and this has major implications for the development of seasonally frozen ground and permafrost.

The characteristics of Arctic snow cover are the result of a complex interplay of atmospheric and surface processes that determine not only the quantity of water stored as snow, but also snowpack condition (e.g., grain size, 